\title{
COMPOSIÇÃO CENTESIMAL DETERMINADA E A DECLARADA DE PÃES DE QUEIJO DE DIFERENTES MARCAS
}

\section{Desafios}

Determined and declared centesimal composition of frozen cheese breads of different brands.

Composición centesimal determinada y declarada de pies de queso congelados de diferentes marcas.

Rodrigo Barbosa Monteiro Cavalcante ${ }^{* 1}$, Maria Lemes Campos Rodrigues Ferro ${ }^{1}$, Renata de Souza Machado ${ }^{1}$, Tiago Dias ${ }^{1}$, Tânia Aparecida Pinto de Castro Ferreira ${ }^{1}$

${ }^{1}$ Curso de Nutrição, Universidade Federal de Goiás, Goiânia, Brasil.

*Correspondência: Universidade Federal de Goiás, Avenida Esperança s/n - Campus Samambaia, Goiânia, Goiás, Brasil.CEP:74.690-900.E-mail rbmc89@hotmail.com

\section{Artigo recebido em 29/04/2019 aprovado em 03/05/2019 publicado em 16/06/2019.}

\section{RESUMO}

O pão de queijo é um produto que apresenta ótima aceitação e a venda de massas congeladas promove maior praticidade e disseminação do produto. O presente estudo visou determinar a composição centesimal e comparar com os teores de macronutrientes e valor calórico contidos nos rótulos de pães de queijo congelados. Foram analisados pães provenientes de 6 marcas. A umidade foi determinada até obtenção de peso constante em estufa a $105{ }^{\circ} \mathrm{C}$ e o teor de cinzas após calcinação das amostras em mufla a $550{ }^{\circ} \mathrm{C}$. O teor de lipídios foi obtido por extração a frio e a concentração de proteínas pelo método Micro-Kjeldahl. Os carboidratos foram calculados por diferença e o valor calórico total de acordo com os fatores de conversão de Atwater. Os pães de queijo analisados apresentaram elevada umidade e teores de cinzas condizentes com o relatado na literatura. Em relação aos macronutrientes, destacaram-se os carboidratos e lipídeos. Conforme os dados obtidos, pode-se caracterizar o pão de queijo como um produto de elevado valor calórico. Apesar da discordância entre os resultados determinados e os declarados, essa comparação deve ser feita com cautela devido à ausência de informações sobre os métodos utilizados na determinação dos constituintes dos rótulos.

Palavras-chave: Produto de panificação; composição química; embalagem.

\section{ABSTRACT}

Cheese bread is a product that presents great acceptance and the sale of frozen pastas promotes greater convenience and product dissemination. The current study aimed to determine the centesimal composition and to compare with the macronutrient and caloric content contained in the labels of frozen cheese loaves. Breads from 6 brands were analyzed. The moisture was determined until constant oven weight at $105^{\circ} \mathrm{C}$ and the ash content after calcination of the samples in muffle at $550^{\circ} \mathrm{C}$. The lipid content was obtained by cold extraction and protein concentration by Micro-Kjeldahl method. Carbohydrates were calculated by difference and the total caloric value according to the Atwater conversion factors. The cheese breads analyzed presented high humidity and ash content consistent with that reported in the literature. In relation to the macronutrients, the carbohydrates and lipids were highlighted. According to the data obtained, it is possible to characterize cheese bread as a product of high calorific value. Despite the discrepancy between the results determined and those declared, this comparison should be made with caution because of the lack of information on the methods used to determine the constituents of the labels.

Keywords: Bakery product; chemical composition; package. 


\section{RESUMEN}

El pan de queso es un producto que presenta óptima aceptación y la venta de masas congeladas promueve mayor practicidad y diseminación del producto. El presente estúdio pretendió determinar la composición centesimal y comparar com los contenidos de macronutrientes y valor calórico contenidos en las etiquetas de panes de queso congelados. Se analizaron panes provenientes de 6 marcas. La humedad se determinó hasta obtener un peso constante em invernadero a $105^{\circ} \mathrm{C}$ y el contenido de cenizas después de calcinación de las muestras en mufla a 550 ${ }^{\circ} \mathrm{C}$. El contenido de lípidos fue obtenido por extracción em frío y la concentración de proteínas por el método Micro-Kjeldahl. Los carbohidratos se calcularon por diferencia y el valor calórico total de acuerdo com los factores de conversión de Atwater. Los panes de queso analizados presentaron elevada humedad y contenidos de cenizas concordantes con lo reportado en la literatura. Encuanto a los macronutrientes, se destacaron los carbohidratos y los lípidos. Conforme a los datos obtenidos, se puede caracterizar el pan de queso como un producto de alto valor calórico. A pesar de la discrepancia entre los resultados determinados y los declarados, esta comparación debe hacerse con cautela debido a la falta de información sobre los métodos utilizados para determinar los constituyentes de las etiquetas.

Descriptores: Producto de panadería; composición química; embalaje.

\section{INTRODUÇÃO}

O pão de queijo é um produto tradicional de Minas Gerais, Brasil, obtido a partir da mistura de polvilho (amido da mandioca) com água ou leite, ovo, queijo, sal e gordura, podendo variar o tipo de polvilho (doce, azedo ou a mistura deles). É um alimento bastante consumido em todo o país e possui tendência de expansão para o mercado externo (Cavalcante et al., 2016; Minim et al., 2000).

Apesar de sua grande importância no mercado, devido ao seu consumo crescente, não possui padronização de fabricação, identidade e qualidade. Assim, diferentes variações do produto podem ser adquiridas no mercado, com características bem distintas, devido à diversidade de ingredientes e preparações (Machado e Pereira, 2010).

O pão de queijo é um produto calórico, visto que sua receita é composta por ingredientes com elevada densidade energética. Além de ser fonte reconhecida de carboidratos, o pão de queijo também é um produto de panificação isento de glúten, o que o coloca como alimento alternativo para pacientes celíacos, alérgicos às proteínas do trigo (Pereira et al., 2004).

Considerando que cada vez mais a população está em busca de alimentos de fácil e rápido preparo, o pão de queijo congelado vem ganhando mais espaço no dia-a-dia das pessoas, além de ir ao encontro da sociedade em relação ao consumo de alimentos isentos de glúten (Fisberg et al., 2009).

Pode-se perceber que houve um aumento na preocupação com a nutrição adequada e com as consequências de uma alimentação incorreta entre as pessoas. Assim, verifica-se a importância de se ter estudos que avaliem a composição química de alimentos industrializados frequentemente consumidos pela população (Zancul, 2004).

A comparação entre os dados obtidos e os dados apresentados pelos fabricantes na embalagem deve ser feita cautelosamente, visto não haver informações sobre quais os métodos utilizados para a determinação dos constituintes nas embalagens (Pereira et al., 2005). Diante do exposto, o presente estudo visou determinar a composição centesimal e comparar com os teores de macronutrientes e valor calórico total contidos nos rótulos de pães de queijo congelados.

\section{MATERIAIS E MÉTODOS}

\section{Local e período do estudo}

As análises foram realizadas no Laboratório de Dietética (LD) e no Laboratório de Nutrição e Análise de Alimentos (LANAL) da Faculdade de 
Nutrição (FANUT) da Universidade Federal de Goiás

(UFG) no período de junho a julho de 2018.

\section{Amostras}

Foram analisados pães de queijo provenientes de 6 marcas que vendem o produto congelado. Os mesmos foram obtidos no comércio varejista local de Goiânia (GO), sendo utilizadas apenas 1 embalagem de cada marca.

\section{Preparo das amostras}

Os pães de queijo da marca 3 (P3) foram assados por 20 minutos a $180{ }^{\circ} \mathrm{C}$ em forno combinado pré-aquecido (5 minutos). Os pães das demais marcas foram assados no mesmo forno préaquecido por um período de 30 minutos a $180{ }^{\circ} \mathrm{C}$.

Após o assamento, os produtos de cada marca foram congelados e triturados em liquidificador industrial para a homogeneização dos pães. Posteriormente, realizou-se a técnica de quarteamento para que as amostras analíticas fossem representativas do todo. Todas as análises de composição centesimal foram realizadas em triplicata.

\section{Composição Centesimal}

-Umidade

Foi determinada pelo método de secagem por dessecação até peso constante. Em uma placa de Petri tarada $\left(105^{\circ} \mathrm{C} / 1 \mathrm{~h}\right)$, foi pesado analiticamente 5 gramas do alimento. Posteriormente, as placas foram levadas a estufa $\left(105^{\circ} \mathrm{C}\right)$ por $6 \mathrm{~h}$. Após esse tempo, procedeu-se a secagem de $1 \mathrm{em}$ 1h até obtenção de peso constante (Aoac, 2005).
Cálculo:

Umidade $(\mathrm{g} / 100 \mathrm{~g})=$

$\underline{(\text { placa +tampa+amostra })(\mathrm{g})-(\text { placa+tampa+amostra ultima pesagem })(\mathrm{g})}$ amostra (g)

x 100

-Resíduo mineral fixo (Cinzas)

O método é baseado na determinação da perda de peso do material submetido à carbonização em chapa aquecedora e após a calcinação realizada em temperatura de $550^{\circ} \mathrm{C}$. Primeiramente, colocou-se 3 gramas das amostras em cadinhos previamente tarados $\left(550^{\circ} \mathrm{C} / 1 \mathrm{~h}\right)$. As amostras foram carbonizadas em chapa aquecedora, depois, colocadas em mufla $550^{\circ} \mathrm{C}$ até que o resíduo virasse cinzas. Em seguida, procedeu-se a secagem das cinzas de $1 \mathrm{em} 1 \mathrm{~h}$ em estufa a $105{ }^{\circ} \mathrm{C}$ até obtenção de peso constante (Aoac, 2005).

Cálculo:

$\operatorname{RMF}(\mathrm{g} / 100 \mathrm{~g})=$

$\underline{\text { (peso do cadinho+cinzas-ultima pesagem })-(\text { peso do cadinho })}$ peso da amostra $(g)$

$\times 100$

\section{-Lipídeos}

Foram determinados por extração a frio pelo método de Bligh \& Dyer. Pesou-se 2 gramas da amostra em tubo de $70 \mathrm{ml}$ com $10 \mathrm{ml}$ de clorofórmio, $20 \mathrm{ml}$ de metanol e $8 \mathrm{ml}$ de água destilada. Agitou-se por 30 minutos a $50 \mathrm{rpm}$ em agitador rotativo e, em seguida, foi adicionado mais $10 \mathrm{ml}$ de clorofórmio, $10 \mathrm{ml}$ de sulfato de sódio $1,5 \%$ e agitado vigorosamente por dois minutos. Posteriormente, centrifugou-se os tubos a 1000 rpm por 2 minutos.

Após a centrifugação, a camada metanólica superior foi descartada e a camada inferior foi filtrada e $5 \mathrm{ml}$ desse filtrado foi transferido para uma placa de 
Petri previamente tarada em estufa $\left(105^{\circ} \mathrm{C} / 1 \mathrm{~h}\right)$. Após a evaporação do solvente em estufa a $105^{\circ} \mathrm{C}$, as placas contendo os lipídeos foram pesadas (Aoac, 2005).

Cálculo:

$$
\text { Lipídeos totais }\left(\frac{g}{100 g}\right)=
$$

[Placa + Lipídeos (ultimo peso) - Placa tarada) $] \times$ 4 / Amostra(g)

x 100

\section{-Proteínas}

Foram determinadas pelo método de MicroKjehdahl. O procedimento foi composto por três etapas: digestão, destilação e titulação. Na digestão, pesou-se $150 \mathrm{mg}$ das amostras em papel manteiga e transferiu-se para tubos de Micro-Kjehdahl com 1g de mistura catalítica e $5 \mathrm{~mL}$ de ácido sulfúrico $\left(\mathrm{H}_{2} \mathrm{SO}_{4}\right)$. Os tubos foram aquecidos em bloco digestor até temperatura de $400^{\circ} \mathrm{C}$. No tubo que representou o "branco", para controle da análise, não foi acrescentada a amostra.

Para destilação os tubos contendo as amostras digeridas foram conectados ao aparelho de destilação e receberam $15 \mathrm{~mL}$ de hidróxido de sódio $(\mathrm{NaOH})$ a 50\%. Na saída do aparelho destilador (ponta do condensador) um erlenmeyer com $10 \mathrm{~mL}$ de solução de ácido bórico a $2 \%$ e 4 gotas de indicador de Andersen recolheu a amônia destilada até um volume de aproximadamente $100 \mathrm{~mL}$.

A titulação foi realizada com solução de ácido clorídrico $(\mathrm{HCl})$ 0,02 N.

Foi introduzido o fator empírico 6,25 para transformar a massa $(\mathrm{g})$ de nitrogênio determinado em massa (g) de proteínas (Aoac, 2005).
Cálculo:

$$
\begin{gathered}
\text { Proteína }(g / 100 g)=\frac{\mathrm{V} \times \mathrm{N} \times \mathrm{fC} \times 14,16}{P(m g)} \times F_{n} \\
\times 100
\end{gathered}
$$

Onde:

$\mathrm{V}=$ volume de $\mathrm{HCl}$ gasto

$\mathrm{N}=$ normalidade do $\mathrm{HCl}$

$\mathrm{fC}=$ Fator de correção do $\mathrm{HCl}$

$\mathrm{P}=$ peso da amostra

$F_{n}=$ fator de conversão do Nitrogênio

\section{-Carboidratos Totais}

Foram obtidos por diferença pela fórmula abaixo (Aoac, 2005).

Cálculo:

Carboidratos totais $=100-($ Umidade + Cinzas + Lipídeos + Proteínas).

Valor Calórico Total (Kcal)

O valor calórico total foi calculado de acordo com os fatores de conversão de Atwater: $9 \mathrm{kcal} / \mathrm{g}$ para lipídeos e 4kcal/g para carboidratos e proteínas (Watt e Merrill, 1963).

\section{RESULTADOS E DISCUSSÃO}

Os teores de umidade determinados foram dentro da faixa de $26,5 \%$ a $41,8 \%$ (tabela 1). De acordo com Brasil (2001) não há exigência para o teor de umidade no produto, apenas na mistura para o preparo de pão de queijo que deve ter valor máximo de $12 \%$. Porém, deve-se verificar que o teor de umidade é um resultado relevante para as condições de embalagem e acondicionamento do produto. Segundo Pereira et al. (2005) quanto maior a umidade na massa de pão de queijo maior será a perda de água após o assamento. 
Tabela 1. Composição centesimal de pão de queijo de diferentes marcas.

\begin{tabular}{|c|c|c|c|c|c|}
\hline Marcas & $\begin{array}{c}\text { Umidade } \\
(\mathrm{g} / \mathbf{1 0 0 g}) \\
(\text { média } \pm \mathrm{DP} *)\end{array}$ & $\begin{array}{c}\text { Cinzas } \\
(\mathrm{g} / 100 \mathrm{~g}) \\
(\text { média } \pm \mathrm{DP} *)\end{array}$ & $\begin{array}{c}\text { Carboidratos } \\
(\mathrm{g} / \mathbf{1 0 0 g}) \\
(\text { média } \pm \text { DP*) }\end{array}$ & $\begin{array}{c}\text { Proteínas } \\
(\mathrm{g} / \mathbf{1 0 0 g}) \\
\text { (média } \pm \mathrm{DP} *)\end{array}$ & $\begin{array}{c}\text { Lipídeos } \\
(\mathrm{g} / \mathbf{1 0 0 g}) \\
(\text { média } \pm \text { DP*) }\end{array}$ \\
\hline P1 & $26,7 \pm 0,1^{\mathrm{d}}$ & $2,7 \pm 0,0^{\mathrm{a}}$ & $54 \pm 0,4^{\mathrm{a}}$ & $4,9 \pm 0,5^{b}$ & $11,7 \pm 0,2^{\mathrm{c}}$ \\
\hline P2 & $41,8 \pm 0,8^{\mathrm{a}}$ & $2,2 \pm 0,0^{\mathrm{c}}$ & $46 \pm 1,1^{\mathrm{b}}$ & $1,1 \pm 0,1^{\mathrm{d}}$ & $8,9 \pm 0,4^{\mathrm{d}}$ \\
\hline P3 & $30 \pm 0,4^{\mathrm{c}}$ & $2,5 \pm 0,0^{\mathrm{b}}$ & $46, \overline{7} \pm 0,5^{\mathrm{b}}$ & $7,7 \pm 0,9^{\mathrm{a}}$ & $13,1 \pm 1,0^{\mathrm{c}}$ \\
\hline P4 & $29 \pm 0,1^{\mathrm{c}}$ & $2,3 \pm 0,1^{\mathrm{c}}$ & $47,8 \pm 2,8^{b}$ & $4,1 \pm 0,7^{\mathrm{c}}$ & $16,8 \pm 2,3^{b}$ \\
\hline P5 & $31, \overline{3} \pm 0,3^{\mathrm{b}}$ & $2,3 \pm 0,0^{c}$ & $44,3 \pm 0,7^{\mathrm{b}}$ & $3,7 \pm 0,2^{c}$ & $18,4 \pm 0,4^{b}$ \\
\hline P6 & $26,5 \pm 0,6^{\mathrm{d}}$ & $2,5 \pm 0,0^{\mathrm{b}}$ & $44,9 \pm 0,8^{\mathrm{b}}$ & $5,5 \pm 0,3^{b}$ & $20,6 \pm 0,6^{\mathrm{a}}$ \\
\hline
\end{tabular}

Letras sobrescritas diferentes na mesma coluna demonstram diferença significativa ( $<<0.001$ ) entre as médias (Tukey's HSD). *DP: desvio padrão da média.

Os teores de cinzas obtidos nas amostras significam a quantidade de resíduo mineral fixo presente nos pães de queijo. Conforme verificado na tabela 1 , os teores variaram de 2,2 a $2,7 \%$, valores esses próximos ao determinado por Cavalcante et al. (2016) que obteve $2,6 \%$ e $2,9 \%$ em pães de queijo padrão e enriquecido com feijão-caupi biofortificado, respectivamente. Diante do exposto, pode-se verificar que a inclusão de novos ingredientes na formulação de pão de queijo pode contribuir para o incremento no teor de cinzas.

Silva et al. (2003) analisaram quatro tipos de pão de queijo e obtiveram teores de carboidratos próximos aos determinados no presente estudo $(44,3$ a 54\%) (tabela 1). O elevado teor de carboidratos em pão de queijo é perfeitamente justificado pela significativa quantidade de fécula de mandioca (polvilho) que participa da formulação do produto.
Os teores de proteínas, em sua maioria, apresentaram-se abaixo do valor médio relatado por Pereira et al. (1999) que foi 5,6\% para amostras comercializadas em massas congeladas. Apenas o pão de queijo da marca 3 (P3) apresentou teor acima dessa média. De acordo com Pereira (2001) a variação no teor protéico pode ser resultado de alimentos como o leite, ovo e o queijo utilizados nas formulações de pão de queijo visto que os mesmos apresentam composição química bastante variável.

Conforme verificado na tabela 1 , os teores de lipídeos variaram de 8,9 a 20,6\%. Este resultado é justificado pela elevada concentração de lipídeos nas matérias-primas utilizadas para a elaboração do produto. Porém, como o pão de queijo não apresenta padronização de formulação e ingredientes, pode-se encorajar estratégias que reduzam os teores de lipídeos nesse produto (Silva et al., 2009).

Tabela 2. Teores de macronutrientes determinados e declarados em pão de queijo congelado de diferentes marcas.

\begin{tabular}{lcccccc}
\hline Marcas & $\begin{array}{c}\text { Carboidratos } \\
\text { (g/100g) }\end{array}$ & \multicolumn{2}{c}{$\begin{array}{c}\text { Proteínas } \\
\text { (g/100g) }\end{array}$} & \multicolumn{2}{c}{$\begin{array}{c}\text { Lipídeos } \\
\text { (g/100g) }\end{array}$} \\
& Determinado Declarado* & $\begin{array}{c}\text { Determinado } \\
\text { Declarado }\end{array}$ & Determinado & Declarado \\
\hline P1 & 54 & 36 & 4,9 & 4 & 11,7 & 10,2 \\
P2 & 46 & 42 & 1,1 & 2,2 & 8,9 & 12,6 \\
P3 & 46,7 & 32 & 7,7 & 6,8 & 13,1 & 14,2 \\
P4 & 47,8 & 40 & 4,1 & 4 & 16,8 & 14 \\
P5 & 44,3 & 26,7 & 3,7 & 6,7 & 18,4 & 26,7 \\
P6 & 44,9 & 40 & 5,5 & 3,2 & 20,6 & 8,8 \\
\hline
\end{tabular}

*teores obtidos das embalagens dos pães de queijo congelados. 
Em relação à composição centesimal determinada e a declarada nas embalagens, os teores de carboidratos declarados nas embalagens de todas as marcas foram subestimados quando comparados aos determinados na presente pesquisa. Os produtos das marcas 1, 3, 4 e 6 declararam teores de proteínas menores do que os determinados no trabalho. No que se refere ao teor de lipídeos, as marcas 1,4 e 6 declararam em suas embalagens valores menores do que os determinados (tabela 2).

Tabela 3. Valor calórico total determinado e o declarado em pão de queijo congelado de diferentes marcas.

\begin{tabular}{|c|c|c|}
\hline Marcas & \multicolumn{2}{|c|}{$\begin{array}{c}\text { Valor Calórico Tota } \\
\text { (Kcal) }\end{array}$} \\
\hline P1 & 341 & 254 \\
\hline P2 & 268,5 & 290 \\
\hline P3 & 335,5 & 286 \\
\hline P4 & 358,8 & 302 \\
\hline P5 & 357,6 & 373,3 \\
\hline P6 & 387 & 242 \\
\hline
\end{tabular}

De acordo com a tabela 3, pode-se verificar que os pães das marcas 1, 3, 4 e 6 declararam valor calórico menor do que os determinados nesta pesquisa. $\mathrm{O}$ intervalo do valor calórico determinado foi de 268,5 a 387 Kcal o que caracteriza o pão de queijo como um produto de elevado valor calórico, visto que sua receita padrão é composta por ingredientes com alta densidade energética (Pereira et al., 2004).

Segundo Pereira et al. (2005) a comparação entre os dados determinados e os dados declarados pelos fabricantes deve ser feita cautelosamente, visto não haver informações sobre quais os métodos utilizados para a determinação dos constituintes dos rótulos.

\section{CONCLUSÃO}

Os pães de queijo analisados apresentaram elevada umidade e teores de cinzas condizentes com o relatado na literatura para esse produto. Em relação aos macronutrientes, verificou-se nos pães teores significativos, com destaque para os carboidratos e lipídeos. Conforme os dados obtidos, pode-se caracterizar o pão de queijo como um produto de elevado valor calórico.

A análise dos pães de queijo revelaram que tanto os macronutrientes quanto o valor calórico total apresentaram diferenças entre os dados determinados e os declarados. Porém, essa comparação deve ser feita com cautela devido à ausência de informações sobre os métodos utilizados na determinação dos constituintes dos rótulos.

\section{AGRADECIMENTO}

Aos laboratórios de Dietética (LD) e de Nutrição e Análise de Alimentos (LANAL), À Faculdade de Nutrição (FANUT) e a Universidade Federal de Goiás (UFG) por terem possibilitado a execução deste trabalho.

Todos os autores declararam não haver qualquer potencial conflito de interesses referente a este artigo. 


\section{REFERÊNCIAS}

ASSOCIATION OF OFFICIAL ANALYTICAL CHEMISTRY - AOAC. Official Methods of Analysis of the AOAC International. $16 \mathrm{ed}$ Arlington: AOAC, 2005. 1025p.

BRASIL. Agência Nacional de Vigilância Sanitária Ministério da Saúde. Consulta Pública ${ }^{\circ}$ 80, de 11 de setembro de 2001. Regulamento Técnico para fixação de identidade e qualidade de massa de pão de queijo e mistura para o preparo de pão de queijo. Diário Oficial da União de 12 de setembro de 2001.

CAVALCANTE, R. B. M.; MORGANO, M. A.; SILVA, K. J. D.; ROCHA, M. M.; ARAÚJO, M. A. M.; MOREIRA-ARAÚJO, R. S. R. Cheese bread enriched with biofortified cowpea flour. Ciência e Agrotecnologia. v. 40, n. 1, p. 97-103, 2016.

FISBERG, R. M.; MARCHIONI, D. M. L.; COLUCCI, A. C. A. Avaliação do consumo alimentar e da ingestão de nutrientes na prática clínica. Arquivos Brasileiros de Endocrinologia \& Metabologia, São Paulo, v. 53, n. 5, p. 617-24, 2009.

MACHADO, A.V.; PEREIRA, J. Efeito do escaldamento nas propriedades tecnológicas $\mathrm{e}$ reológicas da massa e do pão de queijo. Ciência e Agrotecnologia, Lavras, v.34, n.2, p.421-427, Apr. 2010.

MINIM, V. P. R.; MACHADO, P. T.; CANAVESI, E.; PIROZI, M.R.. Perfil sensorial e aceitabilidade de diferentes formulações de pão de queijo. Ciênc. Tecnol. Alim., Campinas, v. 20, n. 2, p. 154 - 159, 2000 .

PEREIRA, J. Caracterização química, física, estrutural e sensorial do pão de queijo. Lavras, MG. Tese de Doutorado. Universidade Federal de Lavras, 2001.
PEREIRA, J.; CIACCO, C. F.; VILELA, E. R.; PEREIRA, R. G. F. A. Função dos ingredientes na consistência da massa e nas características do pão de queijo. Ciência e Tecnologia de Alimentos, Campinas, v. 24, n. 4, p. 494-500, 2004.

PEREIRA, J.; CIACCO, C. F.; VILELA, E. R.; TEIXEIRA, A. L. de S. Féculas fermentadas na fabricação de biscoitos: estudo de fontes alternativas. Ciência e Tecnologia de Alimentos, Campinas, v. 19, n. 2, p. 287-293, maio/ago. 1999.

PEREIRA, J.; SILVA, R. P. G.; NERY, F. C.; VILELA, E. R. Comparação entre a composição química determinada e a declarada na embalagem de diferentes marcas de pão de queijo. Ciência e Agrotecnologia, Lavras, v. 29, n. 3, p. 623-628, 2005.

SILVA, M. R.; GARCIA, G. K. S.; FERREIRA, H. F. Caracterização química, física e avaliação da aceitação de pão de queijo com baixo teor energético. Alimentos e Nutrição, Araraquara, v. 14, n. 1, p. 69-75, 2003.

SILVA, R. P. G.; PEREIRA, J.; NERY, F. C.; VILELA, E. R. Efeito do congelamento nas características físicas e químicas do pão de queijo. Ciência e Agrotecnologia. Lavras, v. 33, n. 1, p. 6, 2009.

WATT, B.; MERRILL, A. L. Composition of foods: raw, processed, prepared. Washington DC: Consumer and Food Economics Research. Divison/Agricultural Service (Agriculture Handbook, 8), 1963.

ZANCUL, M. S. Consumo alimentar de alunos nas escolas de Ensino Fundamental em Ribeirão Preto. 2004. Dissertação de Mestrado - Universidade São Paulo, Ribeirão Preto, 2004. 